\title{
Roles for MYC in the Establishment and Maintenance of Pluripotency
}

\author{
James Chappell and Stephen Dalton \\ Department of Biochemistry and Molecular Biology, Paul D. Coverdell Center for Biomedical \\ and Health Sciences, The University of Georgia, Athens, Georgia 30602 \\ Correspondence: sdalton@uga.edu
}

MYC and MYCN have been directly implicated in the transcriptional regulation of several thousand genes in pluripotent stem cells and possibly contribute to the activity of all transcribed genes. Control of transcription by a pause-release mechanism, recruitment of positive and negative epigenetic regulators, and a general role in transcriptional amplification have all been implicated as part of the broad, overarching mechanism by which MYC controls stem cell biology. As would be anticipated from the regulation of so many genes, MYC is involved in a wide range of cellular processes including cell-cycle control, metabolism, signal transduction, self-renewal, maintenance of pluripotency, and control of cell fate decisions. MYC transcription factors also have clear roles in cell reprogramming and establishment of the pluripotent state. The mechanism by which MYC accomplishes this is now being explored and promises to uncover unexpected facets of general MYC regulation that are likely to be applicable to cancer biology. In this work we review our current understanding of how MYC contributes to the maintenance and establishment of pluripotent cells and how it contributes to early embryonic development.

W ell before MYC was implicated in the establishment and maintenance of pluripotency, it was known as a potent oncogene with roles in transcriptional regulation of metabolism, differentiation, cell lifespan, cell cycle, and cell size control. These functions are all generally relevant to the maintenance and establishment of pluripotent stem cells. Despite this, however, defining the precise mechanism by which MYC functions has been problematic and has led to much confusion. The following discussion will focus on our current understanding of how MYC functions in early embryonic de- velopment, maintenance of stem cell identity, and in somatic cell reprogramming.

\section{MYC AND MYCN ARE FUNCTIONALLY REDUNDANT IN EARLY EMBRYONIC DEVELOPMENT}

The MYC family of basic helix-loop-helix leucine zipper transcription factors consists of MYC, MYCN, and MYCL. DNA binding of MYC family members usually requires heterodimerization with MAX (Myc-associated factor $\mathrm{X})$ through their respective leucine zipper do-

Editors: Chi V. Dang and Robert N. Eisenman

Additional Perspectives on MYC and the Pathway to Cancer available at www.perspectivesinmedicine.org

Copyright (C) 2013 Cold Spring Harbor Laboratory Press; all rights reserved; doi: 10.1101/cshperspect.a014381

Cite this article as Cold Spring Harb Perspect Med 2013;3:a014381 
mains (Blackwood and Eisenman 1991; Blackwell et al. 1993). Knockout studies in mice show that no single MYC family member, or MAX, is essential for early development and that MYCL is completely dispensable for all embryogenesis (Hatton et al. 1996; Shen-Li et al. 2000). Individual knockout of MYC, MYCN, or MAX in mice is inconsequential until around the midgestation stages of development. The expression of MYC and MYCN overlaps considerably before gastrulation, explaining the absence of clear developmental defects in single knockouts in pre- and early postimplantation embryos. At this time point, MAX expression becomes essential as knockout mice at $\sim 5.5-6.5 \mathrm{dpc}$ (days postcoitum) cease development (Shen-Li et al. 2000). As primitive tissues begin to form, the expression patterns of MYC and MYCN change. In midgestation development, when $M Y C$ and $M Y C N$ expression becomes nonoverlapping, tissue-specific defects are observed following deletion of MYC or MYCN. MYC ${ }^{-/-}$embryos, for example, are growth retarded and die before $\sim 10.5$ dpc with cardiac, neural, and vascular abnormalities (Davis et al. 1993; Baudino et al. 2002). $\mathrm{MYCN}^{-/-}$embryos die between 10.5 and $12.0 \mathrm{dpc}$ with defects in several of the visceral organs including lung, heart, liver, gut, and the peripheral and central nervous systems (Charron et al. 1992; Stanton et al. 1992; Sawai et al. 1993).

In a key experiment to evaluate the functional redundancy of $M Y C$ and $M Y C N$ in a developmental context, Malynn and coworkers engineered a mouse in which MYC coding sequences were substituted with MYCN. Mice expressing MYCN under transcriptional control of the MYC locus grew to adulthood, reproduced, and generated fertile offspring with only mild skeletal muscle defects (Malynn et al. 2000). This report is often used as evidence to argue that $M Y C$ and $M Y C N$ are functionally redundant but it is possible that in disease pathogenesis such as cancer, the two family members may have nonequivalent functions (Kawauchi et al. 2012; Roussel and Robinson 2013).

Several reports also implicate key roles for MYC family members in the maintenance, expansion, and differentiation of stem cell popu- lations including pluripotent stem cells, hematopoietic stem cells, and keratinocyte stem cells (Gandarillas and Watt 1997; Laurenti et al. 2008; Wilson et al. 2008). Embryonic stem cells (ESCs) isolated from mice lacking either $M Y C$ or MYCN are capable of long-term self-renewal and remain pluripotent (Malynn et al. 2000), consistent with other studies showing that MYC performs redundant roles in peri-implantation development. Simultaneous deletion of floxed MYC and MYCN alleles, however, destabilize the pluripotent state resulting in differentiation toward endoderm and mesoderm (Smith et al. 2010; Varlakhanova et al. 2010). A similar phenomenon occurs in hematopoietic stem cells, in which loss of either MYC or MYCN expression is largely inconsequential, whereas deficiency of both is lethal (Laurenti et al. 2008). In ESCs ectopic reexpression of MYC or MYCN restores pluripotency (Smith et al. 2010), supporting the idea that MYC and MYCN perform redundant roles in maintaining pluripotent stem cell identity.

\section{MYC PROMOTES THE MAINTENANCE OF PLURIPOTENT STEM CELLS}

Pluripotent stem cells (PSCs) divide symmetrically, generating two equivalent daughter stem cells at each mitosis (Zwaka and Thomson 2005). These cells retain the ability to self-renew over long periods of time and the capacity for differentiation toward multiple lineages associated with the three embryonic germ layers. Under feeder-free conditions, murine PSCs are typically cultured in the presence of an interleukin-6 cytokine family member, such as leukemia inhibitory factor (LIF). LIF serves to maintain pluripotency by binding gp130/LIF receptor heterodimers, resulting in phosphoactivation of the STAT3 transcription factor (Ernst et al. 1996; Niwa et al. 1998). STAT3 then activates target genes involved in cell-cycle control, immortalization, and suppression of differentiation. The first evidence pointing toward MYC playing a role in pluripotency came from the work of Cartwright and coworkers in 2005 (Cartwright et al. 2005). Here, MYC was shown to be a direct downstream transcriptional target 
MYC and Pluripotent Stem Cells

of LIF/STAT3 signaling and that sustained MYC expression could alleviate the requirement for LIF over extended periods of time. Numerous regulatory proteins are responsible for modulating MYC degradation (discussed in Farrell and Sears 2013) and one notable feature of MYC protein in PSCs is its unusually long half-life. Pulse-chase experiments show that MYC stability in PSCs is comparable to oncogenic mutants, such as T58A. This enhanced stability requires canonical PI3K signaling to be active so that GSK-3 $\beta$ activity is suppressed. Once LIF signaling is disrupted in mouse ESCs (mESCs), early differentiation is triggered by the collapse of PI3K activity, the activation of GSK-3 $\beta$ and the degradation of MYC. The down-regulation of MYC and MYCN levels is dependent on loss of both STAT3-dependent transcriptional activation and enhanced MYC protein turnover. Coordination of these events is critical for the transition from the self-renewing, pluripotent state to that of an early, lineage-committed cell.

Although the individual inactivation of MYC or MYCN has no discernible effect on plu- ripotency, their simultaneous loss destabilizes PSCs and results in differentiation toward primitive endoderm and mesoderm lineages (Smith et al. 2010). A key target of MYC in PSCs is the endoderm master regulator, GATA6. Transcriptional repression of GATA6 in PSCs requires MYC, and. following loss of MYC activity, GATA6 levels increase and cells differentiate toward primitive endoderm. MYC also induces a number of miRNA targets that inhibit PSC differentiation (Lin et al. 2009a). One such target is the mir-17-92 cluster (Smith et al. 2010). These miRNAs maintain the rapid cell-division cycle of PSCs by elevating the activity of cyclin-Cdk complexes and by limiting the activity of tumor suppressors, such as members of the retinoblastoma (RB) family and potentially $\mathrm{p} 16^{\mathrm{INK} 4 \mathrm{a}}$. The MYC/MAX network has also been shown to coordinate with BMP-4 signaling to activate phosphatases that repress mitogen-activated protein kinase (MAPK) signaling (Fig. 1) (Hishida et al. 2011; Li et al. 2012; Chappell et al. 2013). This is significant because activation of MAPK signaling by fibroblast growth factors

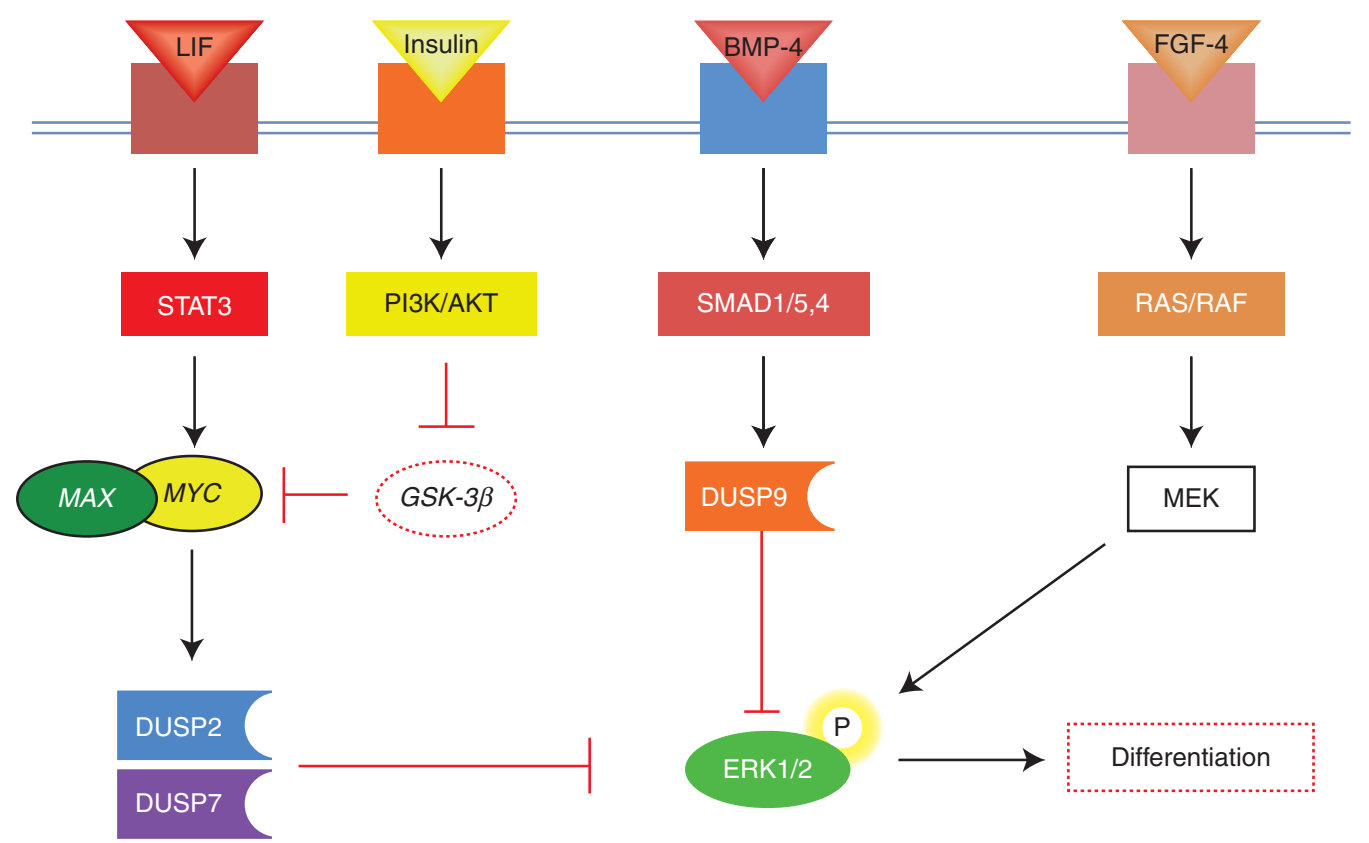

Figure 1. External factors stimulate internal pathways, which cooperate to maintain PSCs. LIF/STAT signaling through MYC and/or BMP signaling through SMAD up-regulate dual-specificity phosphatases (DUSPs) to suppress FGF-stimulated ERK activity, thereby blocking differentiation. 
(FGFs) is known to increase the susceptibility of PSCs to differentiation signals (Kunath et al. 2007). Loss of MYC or MAX in PSCs leads to the down-regulation of ERK phosphatases, DUSP2 and DUSP7, stimulating MAPK signaling and resulting in differentiation (Chappell et al. 2013). The observation that differentiation can be blocked by a small-molecule inhibition of MEK provides an explanation for how PSCs are maintained by MAPK/MEK inhibition in LIF-depleted media (Ying et al. 2008). Under these conditions, self-renewal is not dependent on elevated MYC/MYCN levels (Marks et al. 2012) and implies that a major role for MYC/ MYCN in PSCs is linked to its role as a negative regulator of MAPK signaling.

\section{COMPLEXITIES OF MYC-DEPENDENT TRANSCRIPTIONAL REGULATION IN PLURIPOTENT CELLS}

MYC clearly plays a role in gene activation as part of its overall role in maintaining pluripotency, and this activating function is typically associated with its ability to heterodimerize with MAX at enhancer boxes (E-boxes; 5' -CA CGTG-3') (Blackwood and Eisenman 1991). Recently, MYC has been proposed to regulate all actively transcribed genes in various cell types, including PSCs. In effect, this "universal amplifier" model implicates MYC as a nonlinear amplifier of transcription for all active genes, whereby the amount of MYC bound near a gene's transcription start site is correlated with transcriptional activity. Studies in PSCs indicate that MYC acts at transcription start sites by recruiting factors that release stalled RNA polymerase II complexes, promoting productive transcriptional elongation (Fig. 2A) (Rahl et al. 2010; Lin et al. 2012; Nie et al. 2012). Although this activity is certainly important for enhancing cellular growth and proliferation, the issue of to what extent this activity accounts for the significance of MYC's contribution to pluripotent biology is still unresolved.

Other studies suggest that MYC has important roles that are inadequately encompassed by the universal amplifier model. For example, MYC interacts with a diverse range of epigenetic modifiers to promote open, dynamic chromatin that is accessible to the transcription machinery (Gaspar-Maia et al. 2011; Orkin and Hochedlinger 2011). MYC interacts with TRRAP to recruit components of the GCN5 and NuA4 histone acetyltransferase (HAT) complexes to target genes (McMahon et al. 2000; Lin et al. $2009 b)$. In some cases, this function appears to be important for maintenance of ESC identity, and for the establishment and maintenance of euchromatic chromatin in PSCs by directing H3 and H4 acetylation (Fig. 2A) (Frank et al. 2001; Cotterman et al. 2008). Furthermore, transcriptional repression is also an important MYC function unaccounted for by the universal amplifier model. Besides the repression of GATA6 (Fig. 2B) (Smith et al. 2010), MYC also represses other developmentally important genes, such as the HOX cluster, in collaboration with the POZ domain/Zn-finger transcription factor MIZ-1 (Varlakhanova et al. 2011). MYC also interacts with components of the NuRD repressive complex such as HDAC1, RUVBL1, RUVBL2, and also components of the CoREST complex such as LSD1 (Smith et al. 2011). Interestingly, MYC has been shown in Drosophila to negatively autoregulate its own transcription through a polycomb-dependent mechanism (Khan et al. 2009). It remains unclear whether polycomb complexes broadly play a role in MYC-mediated transcriptional repression, but it is interesting to note that $\sim 10 \%$ of MYC-binding sites are cooccupied by the polycomb subunit SUZ12 and by the H3K27 trimethyl mark (Lin et al. 2009b).

Over the last several years, ChIP-Chip and ChIP-Seq have been critical for defining gene regulatory networks in PSCs that are controlled by core pluripotency factors, such as OCT4 and NANOG (Chen et al. 2008; Kidder et al. 2008; Lin et al. 2009b; Sridharan et al. 2009; Kim et al. 2010; Smith et al. 2011). Similarly, these genome-wide binding studies have determined that MYC binds, and possibly regulates, the transcription of at least 8000 genes in PSCs (Smith et al. 2011). Despite MYC being critical for pluripotency, it clearly regulates a set of genes distinct from those regulated by core pluripotency factors. This set of genes termed the "MYC module" suggests a somewhat contrasted 

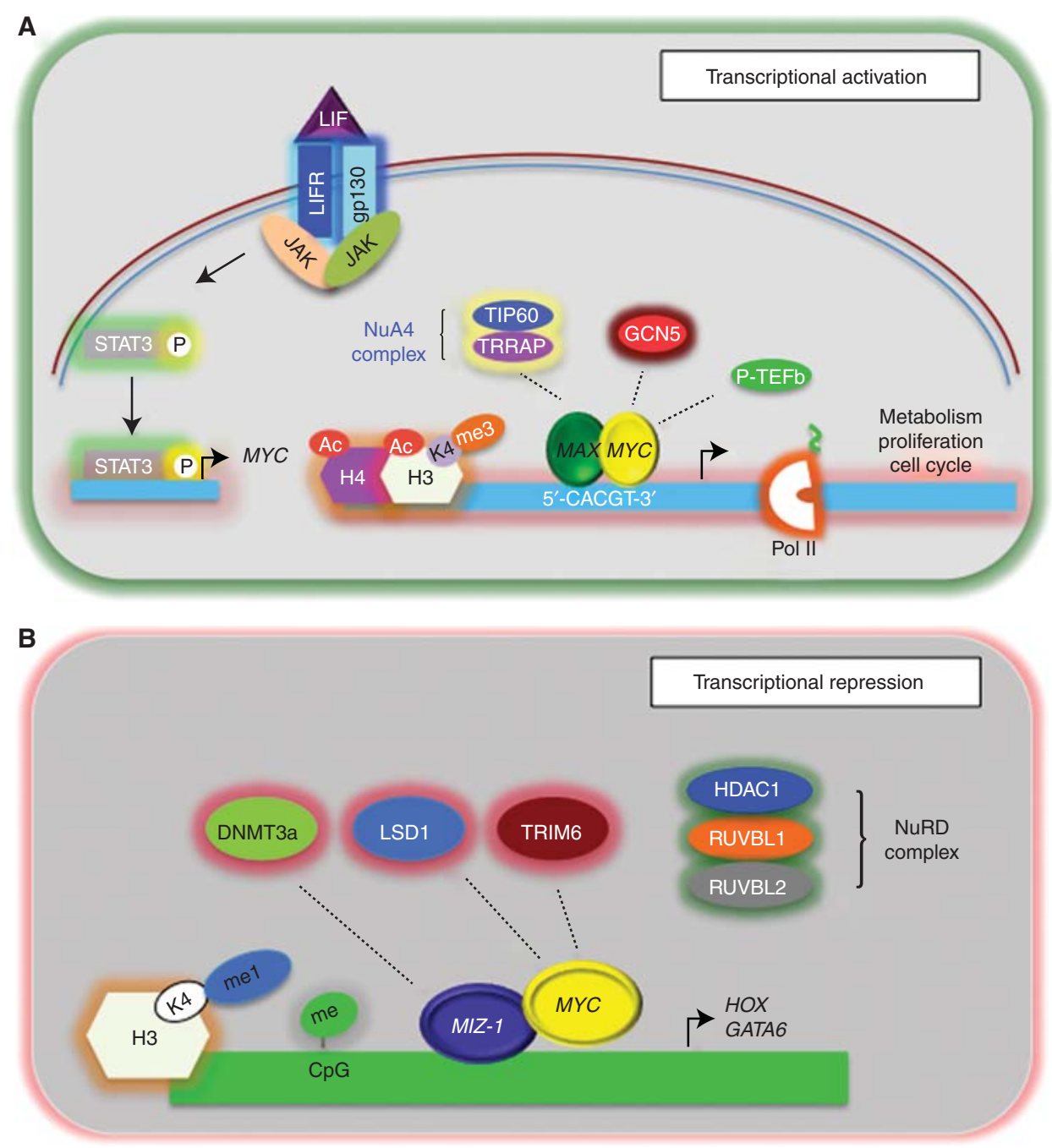

Figure 2. (A) LIF/STAT signaling stimulates transcription of MYC, which then heterodimerizes at E-boxes with MAX and amplifies transcription of active genes. MYC promotes productive transcriptional elongation by releasing stalled RNA polymerase II at transcription start sites. MYC promotes open, accessible chromatin by recruiting components of the MLL histone methyltransferase complex, such as GCN5, and by interacting with HATs, such as the NuA4 complex, which is important for PSC identity and maintenance of euchromatic chromatin. (B) MYC has been shown to act as a transcriptional repressor of developmentally important lineage specifiers, such as GATA6 and HOX genes, by interacting with MIZ-1 and components of the NuRD repressive complex such as HDAC1, RUVBL1, RUVBL2, and also components of the CoREST complex such as LSD1.

role for MYC compared with the universal amplifier model described above (Chen et al. 2008; Kim et al. 2010). In this model, MYC functions to regulate only a subset of genes, many of which are distinctly important for the maintenance of self-renewal and pluripotency. Interestingly, the MYC module can also be identified in cancer cells, implying that MYCs role in pluripotency is related to its function in tumorigenicity (Kim et al. 2010; Rothenberg et al. 2010). Analysis of the MYC module reveals that MYC functions to regulate gene networks important for self-renewal such as growth, metabolism, and cell-cycle progression. Closer examination reveals that 
specific targets associated with pluripotency have been identified. For example, MYC binds and regulates the SOX2 gene (Lin et al. 2009b). This is significant because minor fluctuations in SOX2 expression have been shown to have a dramatic effect on PSC maintenance (Niakan et al. 2010). MYC also induces expression of the polycomb repressive complex components both directly, as in BMI1 (Guney et al. 2006), and indirectly as in EZH2 (Kaur and Cole 2013), which can then repress lineage-specifying genes downstream (Boyer et al. 2006). MYC also regulates self-renewal and pluripotency by transcriptionally activating microRNAs that inhibit differentiation and promote cell division (Lin et al. 2009a). One example is the mir-17-92 cluster that inhibits expression of cell-cycle genes such as E2F1, CCND1, and RB2 (Smith et al. 2010).

\section{ESTABLISHMENT OF PLURIPOTENCY}

Shinya Yamanaka's Nobel Prize winning work shows that forced expression of four transcription factors, OCT4/SOX2/KLF4/MYC (OSKM), was sufficient to reprogram a differentiated somatic cell to an induced pluripotent stem cell (iPSC) state (Takahashi and Yamanaka 2006). This discovery complemented previous work that showed the concept of reprogramming by nuclear transfer technologies (Gurdon et al. 1958; Gurdon and Uehlinger 1966) but in addition, created new opportunities for human disease modeling, drug screening, and regenerative medicine. Many variations to Yamanaka's original approach have now been described (Buganim et al. 2012), including the substitution of MYC with other factors including the histone deacetylase (HDAC) inhibitors valproic acid (Huangfu et al. 2008) and trichostatin A (Araki et al. 2011). Presumably, these factors mimic the effects of MYC in the reprogramming process by promoting the formation of euchromatin. Reprogramming in the absence of ectopically expressed $M Y C$, however, is generally less efficient and delayed relative to when MYC-containing reprogramming cocktails are used (Nakagawa et al. 2008). As mentioned above, MYC can be omitted from reprogramming cocktails but questions have been raised as to the quality of reprogrammed cells generated under different conditions. One recent report provides evidence that MYC is essential to generate fully reprogrammed cells and that this is dependent on its ability to recruit HAT complexes to target genes (Araki et al. 2011). The use of wild-type MYC in clinical settings to generate PSCs is currently not favored because of its potential to deregulate cell proliferation (Okita et al. 2007) but one group recently showed that the ability of MYC to reprogram may be independent of its role in transformation (Nakagawa et al. 2010). They showed that utilizing MYCL, or transformation defective MYC mutants, leads to a decrease in tumorigenicity. This opens up the possibility that other forms of MYC may have utility; however, because MYCL has been associated with some tumors, this phenomenon demands further investigation.

Of the four individual Yamanaka factors, MYC has the most potent effect on being able to establish a PSC-like gene expression profile and appears to exert its effects early in the reprogramming process (Mikkelsen et al. 2008; Sridharan et al. 2009). A novel mechanism was recently described demonstrating that MYC functions as an enhancer of OSK binding to inaccessible chromatin in the early stages of reprogramming (Soufi et al. 2012). OSK serve as "pioneer factors" by engaging enhancers of genes required for the establishment of pluripotency. MYC then binds modified enhancer boxes nearby and enhances the reprogramming process by a mechanism that is yet undetermined, but likely involves recruitment of chromatin-opening cofactors. At later stages of reprogramming, the combined effects of OKSM render chromatin more accessible around key pluripotency genes and colocalization of OSKM is lost as each factor resolves to their respective binding sites (Fig. 3). This novel function in early reprogramming appears to be independent of transcriptional regulation, indicating that the universal amplifier model, discussed above, may be more applicable to MYC's role in stem cell maintenance than to establishment of pluripotency. Interestingly, this permissive role of MYC may be similar to the way in which aber- 


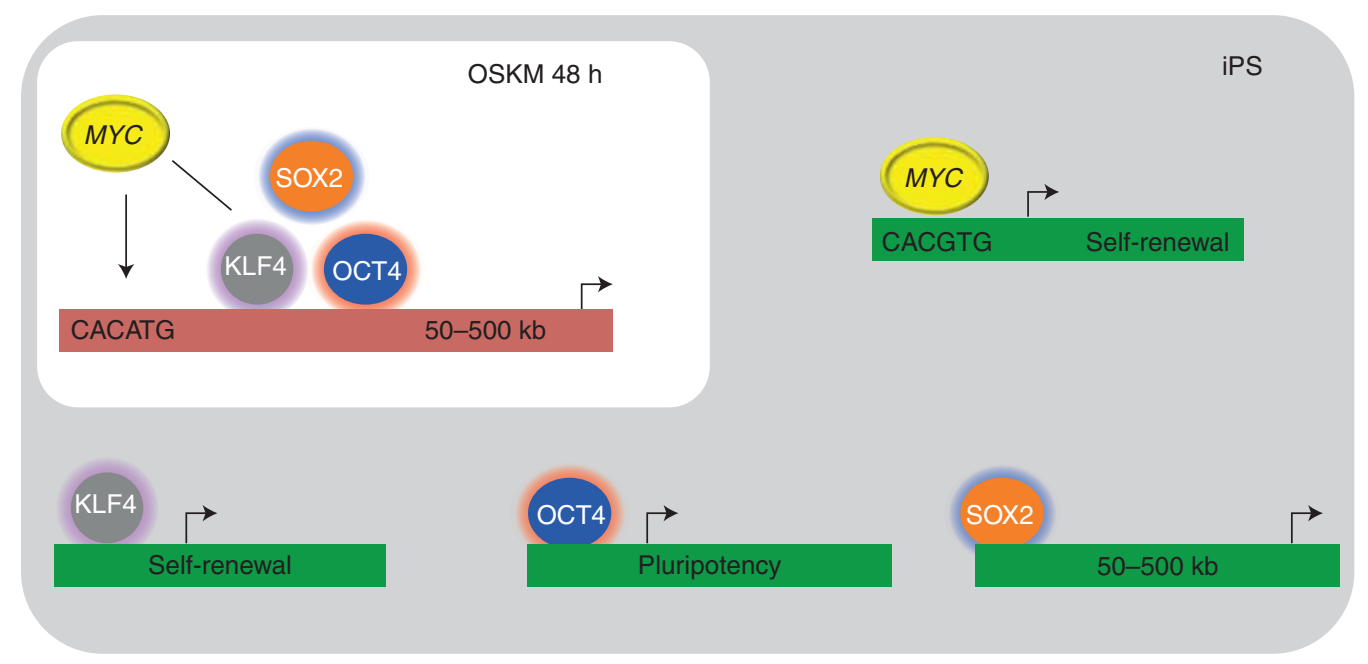

Figure 3. OSK act as "pioneer factors" in reprogramming. MYC stabilizes and enhances binding of OSK to regulatory regions in the first 48 hours. This involves transient binding of MYC to noncanonical E-boxes, resulting in the reinforcement of OSK binding. This promotes euchromatin formation that renders promoters accessible in fully reprogrammed cells. MYC, OCT4, and KLF4 can then bind their respective target gene promoters at more proximal sites and then activate transcription. Unlike OKM, SOX2 remains enriched at distal enhancers.

rant overexpression can lead to transformation upon accumulation of other mutations in the context of tumorigenesis. More work needs to be performed to fully understand the mechanics and detailed temporal aspects of reprogramming.

\section{CONCLUSIONS}

MYC clearly plays an essential role in the processes that underpin early embryonic development and pluripotent stem cell biology. Functions in promoting transcriptional activation of genes responsible for self-renewal and those imposing a differentiation blockade have been well documented but exactly how these influence reprogramming at the molecular level remains an important problem. PSCs are likely to provide a critical biological platform for deciphering how MYC functions in a wide range of biological contexts.

\section{ACKNOWLEDGMENTS}

This work is supported by grants to S.D. from the National Institute of Child Health and $\mathrm{Hu}-$ man Development (HD049647) and the National Institute for General Medical Sciences (GM75334).

\section{REFERENCES}

* Reference is also in this collection.

Araki R, Hoki Y, Uda M, Nakamura M, Jincho Y, Tamura C, Sunayama M, Ando S, Sugiura M, Yoshida MA, et al. 2011. Crucial role of c-Myc in the generation of induced pluripotent stem cells. Stem Cells 29: 1362-1370.

Baudino TA, McKay C, Pendeville-Samain H, Nilsson JA, Maclean KH, White EL, Davis AC, Ihle JN, Cleveland JL. 2002. c-Myc is essential for vasculogenesis and angiogenesis during development and tumor progression. Genes Dev 16: 2530-2543.

Blackwell TK, Huang J, Ma A, Kretzner L, Alt FW, Eisenman RN, Weintraub H. 1993. Binding of myc proteins to canonical and noncanonical DNA sequences. Mol Cell Biol 13: 5216-5224.

Blackwood EM, Eisenman RN. 1991. Max: A helix-loop-helix zipper protein that forms a sequence-specific DNAbinding complex with Myc. Science 251: 1211-1217.

Boyer LA, Plath K, Zeitlinger J, Brambrink T, Medeiros LA, Lee TI, Levine SS, Wernig M, Tajonar A, Ray MK, et al. 2006. Polycomb complexes repress developmental regulators in murine embryonic stem cells. Nature 441: 349-353.

Buganim Y, Faddah DA, Cheng AW, Itskovich E, Markoulaki S, Ganz K, Klemm SL, van Oudenaarden A, Jaenisch R. 
J. Chappell and S. Dalton

2012. Single-cell expression analyses during cellular reprogramming reveal an early stochastic and a late hierarchic phase. Cell 150: 1209-1222.

Cartwright P, McLean C, Sheppard A, Rivett D, Jones K, Dalton S. 2005. LIF/STAT3 controls ES cell self-renewal and pluripotency by a Myc-dependent mechanism. Development 132: 885-896.

Chappell J, Sun Y, Singh A, Dalton S. 2013. MYC/MAX control ERK signaling and pluripotency by regulation of dual-specificity phosphatases 2 and 7. Genes Dev 27: $725-733$.

Charron J, Malynn BA, Fisher P, Stewart V, Jeannotte L, Goff SP, Robertson EJ, Alt FW. 1992. Embryonic lethality in mice homozygous for a targeted disruption of the N-myc gene. Genes Dev 6: 2248-2257.

Chen X, Xu H, Yuan P, Fang F, Huss M, Vega VB, Wong E, Orlov YL, Zhang W, Jiang J, et al. 2008. Integration of external signaling pathways with the core transcriptional network in embryonic stem cells. Cell 133: 1106-1117.

Cotterman R, Jin VX, Krig SR, Lemen JM, Wey A, Farnham PJ, Knoepfler PS. 2008. N-Myc regulates a widespread euchromatic program in the human genome partially independent of its role as a classical transcription factor. Cancer Res 68: 9654-9662.

Davis AC, Wims M, Spotts GD, Hann SR, Bradley A. 1993. A null c-myc mutation causes lethality before 10.5 days of gestation in homozygotes and reduced fertility in heterozygous female mice. Genes Dev 7: 671-682.

Ernst M, Oates A, Dunn AR. 1996. Gp130-mediated signal transduction in embryonic stem cells involves activation of Jak and Ras/mitogen-activated protein kinase pathways. J Biol Chem 271: 30136-30143.

* Farrell AS, Sears RC. 2013. MYC degradation. Cold Spring Harb Perspect Med doi: 10.1101/cshperspect.a014365.

Frank SR, Schroeder M, Fernandez P, Taubert S, Amati B. 2001. Binding of c-Myc to chromatin mediates mitogeninduced acetylation of histone $\mathrm{H} 4$ and gene activation. Genes Dev 15: 2069-2082.

Gandarillas A, Watt FM. 1997. c-Myc promotes differentiation of human epidermal stem cells. Genes Dev 11:28692882.

Gaspar-Maia A, Alajem A, Meshorer E, Ramalho-Santos M. 2011. Open chromatin in pluripotency and reprogramming. Nat Rev Mol Cell Biol 12: 36-47.

Guney I, Wu S, Sedivy JM. 2006. Reduced c-Myc signaling triggers telomere-independent senescence by regulating Bmi-1 and p16(INK4a). Proc Natl Acad Sci 103: 36453650.

Gurdon JB, Uehlinger V. 1966. "Fertile" intestine nuclei. Nature 210: $1240-1241$.

Gurdon JB, Elsdale TR, Fischberg M. 1958. Sexually mature individuals of Xenopus laevis from the transplantation of single somatic nuclei. Nature 182: 64-65.

Hatton KS, Mahon K, Chin L, Chiu FC, Lee HW, Peng D, Morgenbesser SD, Horner J, DePinho RA. 1996. Expression and activity of L-Myc in normal mouse development. Mol Cell Biol 16: 1794-1804.

Hishida T, Nozaki Y, Nakachi Y, Mizuno Y, Okazaki Y, Ema M, Takahashi S, Nishimoto M, Okuda A. 2011. Indefinite self-renewal of ESCs through Myc/Max transcriptional complex-independent mechanisms. Cell Stem Cell $\mathbf{9}$ 37-49.

Huangfu D, Maehr R, Guo W, Eijkelenboom A, Snitow M, Chen AE, Melton DA. 2008. Induction of pluripotent stem cells by defined factors is greatly improved by small-molecule compounds. Nat Biotechnol 26: 795797.

Kaur M, Cole MD. 2013. MYC acts via the PTEN tumor suppressor to elicit autoregulation and genome-wide gene repression by activation of the Ezh2 methyltransferase. Cancer Res 73: 695-705.

Kawauchi D, Robinson G, Uziel T, Gibson P, Rehg J, Gao C, Finkelstein D, Qu C, Pounds S, Ellison DW, et al. 2012. A mouse model of the most aggressive subgroup of human medulloblastoma. Cancer Cell 21: 168-180.

Khan A, Shover W, Goodliffe JM. 2009. Su(z)2 antagonizes auto-repression of Myc in Drosophila, increasing Myc levels and subsequent trans-activation. PloS ONE 4: e5076.

Kidder BL, Yang J, Palmer S. 2008. Stat3 and c-Myc genomewide promoter occupancy in embryonic stem cells. PloS ONE 3: e3932.

Kim J, Woo AJ, Chu J, Snow JW, Fujiwara Y, Kim CG, Cantor AB, Orkin SH. 2010. A Myc network accounts for similarities between embryonic stem and cancer cell transcription programs. Cell 143: 313-324.

Kunath T, Saba-El-Leil MK, Almousailleakh M, Wray J, Meloche S, Smith A. 2007. FGF stimulation of the Erk1/2 signalling cascade triggers transition of pluripotent embryonic stem cells from self-renewal to lineage commitment. Development 134: 2895-2902.

Laurenti E, Varnum-Finney B, Wilson A, Ferrero I, BlancoBose WE, Ehninger A, Knoepfler PS, Cheng PF, MacDonald HR, Eisenman RN, et al. 2008. Hematopoietic stem cell function and survival depend on c-Myc and N-Myc activity. Cell Stem Cell 3: 611-624.

Li Z, Fei T, Zhang J, Zhu G, Wang L, Lu D, Chi X, Teng Y, Hou N, Yang X, et al. 2012. BMP4 Ssignaling acts via dualspecificity phosphatase 9 to control ERK activity in mouse embryonic stem cells. Cell Stem Cell 10: 171-182.

Lin CH, Jackson AL, Guo J, Linsley PS, Eisenman RN. 2009a. Myc-regulated microRNAs attenuate embryonic stem cell differentiation. EMBO J 28: 3157-3170.

Lin CH, Lin C, Tanaka H, Fero ML, Eisenman RN. 2009b. Gene regulation and epigenetic remodeling in murine embryonic stem cells by c-Myc. PloS ONE 4: e7839.

Lin CY, Loven J, Rahl PB, Paranal RM, Burge CB, Bradner JE, Lee TI, Young RA. 2012. Transcriptional amplification in tumor cells with elevated c-Myc. Cell 151: 56-67.

Malynn BA, de Alboran IM, O’Hagan RC, Bronson R, Davidson L, DePinho RA, Alt FW. 2000. N-myc can functionally replace c-myc in murine development, cellular growth, and differentiation. Genes Dev 14: 1390-1399.

Marks H, Kalkan T, Menafra R, Denissov S, Jones K, Hofemeister H, Nichols J, Kranz A, Stewart AF, Smith A, et al. 2012. The transcriptional and epigenomic foundations of ground state pluripotency. Cell 149: 590-604.

McMahon SB, Wood MA, Cole MD. 2000. The essential cofactor TRRAP recruits the histone acetyltransferase hGCN5 to c-Myc. Mol Cell Biol 20: 556-562. 
Mikkelsen TS, Hanna J, Zhang X, Ku M, Wernig M, Schorderet P, Bernstein BE, Jaenisch R, Lander ES, Meissner A. 2008. Dissecting direct reprogramming through integrative genomic analysis. Nature 454: 49-55.

Nakagawa M, Koyanagi M, Tanabe K, Takahashi K, Ichisaka T, Aoi T, Okita K, Mochiduki Y, Takizawa N, Yamanaka S. 2008. Generation of induced pluripotent stem cells without Myc from mouse and human fibroblasts. Nat Biotechnol 26: 101-106.

Nakagawa M, Takizawa N, Narita M, Ichisaka T, Yamanaka S. 2010. Promotion of direct reprogramming by transformation-deficient Myc. Proc Natl Acad Sci 107: 14152 14157.

Niakan KK, Ji H, Maehr R, Vokes SA, Rodolfa KT, Sherwood RI, Yamaki M, Dimos JT, Chen AE, Melton DA, et al. 2010. Sox 17 promotes differentiation in mouse embryonic stem cells by directly regulating extraembryonic gene expression and indirectly antagonizing self-renewal. Genes Dev 24: 312-326.

Nie Z, Hu G, Wei G, Cui K, Yamane A, Resch W, Wang R, Green DR, Tessarollo L, Casellas R, et al. 2012. c-Myc is a universal amplifier of expressed genes in lymphocytes and embryonic stem cells. Cell 151: 68-79.

Niwa H, Burdon T, Chambers I, Smith A. 1998. Self-renewal of pluripotent embryonic stem cells is mediated via activation of STAT3. Genes Dev 12: 2048-2060.

Okita K, Ichisaka T, Yamanaka S. 2007. Generation of germline-competent induced pluripotent stem cells. Nature 448: $313-317$.

Orkin SH, Hochedlinger K. 2011. Chromatin connections to pluripotency and cellular reprogramming. Cell 145: 835-850.

Rahl PB, Lin CY, Seila AC, Flynn RA, McCuine S, Burge CB, Sharp PA, Young RA. 2010. c-Myc regulates transcriptional pause release. Cell 141: 432-445.

Rothenberg ME, Clarke MF, Diehn M. 2010. The Myc connection: ES cells and cancer. Cell 143: 184-186.

* Roussel MF, Robinson GW. 2013. Role of MYC in medulloblastoma. Cold Spring Harb Perspect Med 3: a014308.

Sawai S, Shimono A, Wakamatsu Y, Palmes C, Hanaoka K, Kondoh H. 1993. Defects of embryonic organogenesis resulting from targeted disruption of the $\mathrm{N}-m y c$ gene in the mouse. Development 117: 1445-1455.
Shen-Li H, O’Hagan RC, Hou H Jr, Horner JW II, Lee HW, DePinho RA. 2000. Essential role for Max in early embryonic growth and development. Genes Dev 14: 17-22.

Smith KN, Singh AM, Dalton S. 2010. Myc represses primitive endoderm differentiation in pluripotent stem cells. Cell Stem Cell 7: 343-354.

Smith KN, Lim JM, Wells L, Dalton S. 2011. Myc orchestrates a regulatory network required for the establishment and maintenance of pluripotency. Cell Cycle 10: $592-$ 597.

Soufi A, Donahue G, Zaret KS. 2012. Facilitators and impediments of the pluripotency reprogramming factors initial engagement with the genome. Cell 151: 994-1004.

Sridharan R, Tchieu J, Mason MJ, Yachechko R, Kuoy E, Horvath S, Zhou Q, Plath K. 2009. Role of the murine reprogramming factors in the induction of pluripotency. Cell 136: 364-377.

Stanton BR, Perkins AS, Tessarollo L, Sassoon DA, Parada LF. 1992. Loss of N-myc function results in embryonic lethality and failure of the epithelial component of the embryo to develop. Genes Dev 6: 2235-2247.

Takahashi K, Yamanaka S. 2006. Induction of pluripotent stem cells from mouse embryonic and adult fibroblast cultures by defined factors. Cell 126: 663-676.

Varlakhanova NV, Cotterman RF, deVries WN, Morgan J, Donahue LR, Murray S, Knowles BB, Knoepfler PS. 2010. myc maintains embryonic stem cell pluripotency and self-renewal. Differentiation 80: 9-19.

Varlakhanova N, Cotterman R, Bradnam K, Korf I, Knoepfler PS. 2011. Myc and Miz-1 have coordinate genomic functions including targeting Hox genes in human embryonic stem cells. Epigenetics Chromatin 4: 20.

Wilson A, Laurenti E, Oser G, van der Wath RC, BlancoBose W, Jaworski M, Offner S, Dunant CF, Eshkind L, Bockamp E, et al. 2008. Hematopoietic stem cells reversibly switch from dormancy to self-renewal during homeostasis and repair. Cell 135: 1118-1129.

Ying QL, Wray J, Nichols J, Batlle-Morera L, Doble B, Woodgett J, Cohen P, Smith A. 2008. The ground state of embryonic stem cell self-renewal. Nature 453: 519-523.

Zwaka TP, Thomson JA. 2005. Differentiation of human embryonic stem cells occurs through symmetric cell division. Stem Cells 23: 146-149. 


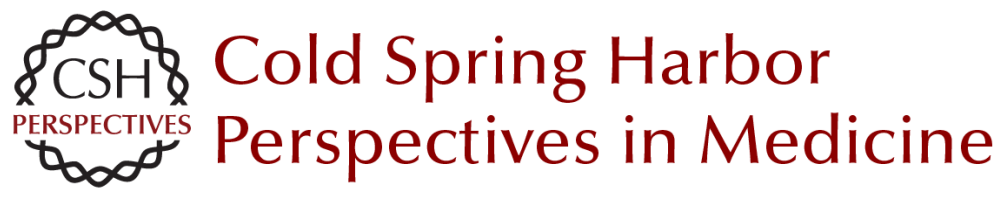

\section{Roles for MYC in the Establishment and Maintenance of Pluripotency}

James Chappell and Stephen Dalton

Cold Spring Harb Perspect Med 2013; doi: 10.1101/cshperspect.a014381

Subject Collection MYC and the Pathway to Cancer

MYC Cofactors: Molecular Switches Controlling

Diverse Biological Outcomes Stephen R. Hann

MYC Association with Cancer Risk and a New

Model of MYC-Mediated Repression Michael D. Cole

MYC and the Art of MicroRNA Maintenance James N. Psathas and Andrei Thomas-Tikhonenko

MYC Activation Is a Hallmark of Cancer Initiation and Maintenance

Meital Gabay, Yulin Li and Dean W. Felsher

MYC and Mitochondrial Biogenesis Fionnuala Morrish and David Hockenbery

Synthetic Lethal Screens as a Means to

Understand and Treat MYC-Driven Cancers Silvia Cermelli, In Sock Jang, Brady Bernard, et al.

An Overview of MYC and Its Interactome Maralice Conacci-Sorrell, Lisa McFerrin and Robert N. Eisenman

Socializing with MYC: Cell Competition in Development and as a Model for Premalignant Cancer

Laura A. Johnston
MYC and the Control of Apoptosis Steven B. McMahon

Therapeutic Strategies to Inhibit MYC Michael R. McKeown and James E. Bradner

MYC and the Control of DNA Replication David Dominguez-Sola and Jean Gautier

MYC Regulation of Cell Growth through Control of Transcription by RNA Polymerases I and III Kirsteen J. Campbell and Robert J. White

MYC Degradation Amy S. Farrell and Rosalie C. Sears

MYC and Transcription Elongation Peter B. Rahl and Richard A. Young

c-MYC-Induced Genomic Instability Alexandra Kuzyk and Sabine Mai

Oncogenic Mechanisms in Burkitt Lymphoma Roland Schmitz, Michele Ceribelli, Stefania Pittaluga, et al.

For additional articles in this collection, see http://perspectivesinmedicine.cshlp.org/cgi/collection/ 